\title{
Caso Nueva Costa del Plata: conflicto, espacialización y territorialización en Avellaneda y Quilmes
}

\author{
The case of New Costa Del Plata: conflict, spatialization and territorialization in Avellaneda and Quilmes \\ Vanina P. Santy \\ Centro de Antropología Cultural Facultad de Filosofia y Ciencias Sociales \\ Universidad Libre de Bruselas, Bélgica \\ vanina.santy@ulb.ac.be
}

\section{ResUMen:}

Este artículo se propone reflexionar sobre los resultados preliminares de investigación en torno al conflicto generado por la urbanización de la ribera sur del Gran Buenos Aires con el proyecto Nueva Costa del Plata (NCP). Analizaré las formas de la producción social de este espacio en el marco de las diferencias entre diversos actores por el destino del lugar. Lo haré desde la teoría espacial Lefebvriana, presentando asimismo los límites encontrados en la espacialización para el análisis de la resistencia vecinal que se opone a dicha transformación. El proceso de territorialización brindará un aporte suplementario para mostrar otros aspectos de esta particular lucha que ya lleva una década. El abordaje combina la geografía, la ecología política y la antropología a fin de mostrar una perspectiva diferente de conflicto en la gestión de las últimas áreas de valor ecológico de la ciudad.

Palabras Clave: Nueva Costa del Plata, Conflicto, Producción espacial, Territorio, Identidad colectiva.

\section{Abstract:}

This article aims to reflect on preliminary research results on the conflict generated by the urbanization of the southern riverside of Greater Buenos Aires by means of the project Nueva Costa del Plata (NCP). I will analyze the forms of social space production in the context of the differences between multiple actors over its destination. I will do it from the Lefebvrian spacial theory, also putting forward the limits found in spatialization for the analysis of neighbor resistance opposing that transformation. The process of territorialization will enable the additional show of other aspects of this particular decade-long struggle. The approach combines geography, political ecology, and anthropology in order to show a different conflict perspective in relation to the management of the last areas of ecological value in the city.

KEYWORDS: Nueva Costa del Plata, Conflict, Space production, Territory, Collective identity.

\section{INTRODUCCIÓN}

La obra La producción del espacio (Lefebvre, 1974) es un clásico contemporáneo que continúa brindando posibilidades para pensar la complejidad, continuidades y contradicciones de la reorganización territorial. Tanto en Francia como en el mundo anglosajón, su trabajo continúa siendo publicado y su pensamiento desarrollado por diferentes disciplinas en una línea crítica de lo urbano.

Edward Soja (1996), por caso, concibió una perspectiva alternativa al dualismo material y mental que caracterizaba lo espacial en ese entonces. Reinterpretó los tres momentos de la producción del espacio (lo percibido, lo concebido y lo vivido) del sociólogo francés para crear el concepto de tercer espacio. Él mismo replanteó a la producción espacial como un proceso más bien expansivo y articulador de la epistemología, la ontología y la historicidad. Ulrich Oslender (2016) puso el acento en lo espacial para explicar la constitución geográfica de la agencia de movimientos sociales. El río, concluyó, juega un rol central en las relaciones humanas y no humanas que se entremezclan en el lugar acuático del Pacífico Colombiano. Al igual que Lefebvre, para Oslender el espacio es la fuente y objetivo del conflicto político. En su estudio sobre las transformaciones del espacio social de Chiapas, México, Rosa Fernández de la Fuente (2002, p. 25) fue más 
allá para considerar al espacio como "hecho social". El espacio es el resultado del devenir conflictivo entre imaginaciones hegemónicas y resistidas; de allí surgen a su vez nuevas formas de pensar al espacio, las cuales conforman prácticas y valorizaciones que inciden en él. Lefebvre también influyó en David Harvey (2012), quien llegó a reflexionar sobre la función de la ciudad moderna como centro de acumulación capitalista, en el que las decisiones financieras y los desarrolladores urbanos controlan el acceso a sus recursos. El "derecho a la ciudad", otro postulado Lefebvriano, se expresa no sólo en formas de lucha política por la producción sociocultural del espacio urbano (Marcús, 2017), sino además en prácticas cotidianas que bregan por la circulación y distribución de servicios que hacen a lo urbano (Swyngedouw, 2004).

El caso NCP forma parte de una categoría de creciente conflictividad en la ciudad que se configura en torno a la naturaleza. El sur del Gran Buenos Aires se distingue por la movilización social en pro de la conservación de áreas protegidas. Cabe mencionarse aquí los enfrentamientos suscitados por la reserva natural integral y mixta de la Laguna de Rocha (Esteban Echeverría), la reserva de Santa Catalina (Lomas de Zamora), y de las zonas costeras de Berazategui, con Hudson a la cabeza.

Consideradas como espacios asociados a la vida, estas zonas de bosques y humedales se convierten cada vez más en el foco de acciones estratégicamente orientadas por diferentes actores.

Para el caso que aquí se presenta, el espacio podría definirse como una compleja red de relaciones de poder/saber de dominación y de resistencia que se expresan a nivel material (prácticas y discursos) y simbólico (elementos imaginarios). El resultado es la superposición de visiones que dan forma a un espacio a través de múltiples espacios, con la apropiación, la ocupación y la alteración de sus condiciones físicas, espaciales y sociales. La costa de Avellaneda y Quilmes se caracteriza particularmente por la interacción de procesos, actores, y las formas de intervención que estos despliegan allí. A partir de la dialéctica entre los tres momentos de producción espacial, con las prácticas espaciales, las representaciones del espacio y los espacios de representación, se logró establecer que las formas de usar el territorio y las tensiones que ello genera se extienden más allá de quienes se enfrentan por NCP. El término que mejor podría describir estos procesos sería la complejidad, la cual está dada por la cantidad de elementos a tener en cuenta y por la manera en que se entretejen. La espacialización y la territorialización intentan encauzar esta complejidad para explicar cómo se ha dado recientemente esto.

A fin de indagar sobre estas cuestiones se tomará como marco temporal el período que va desde la aparición pública de NCP hasta el presente, por lo tanto, el artículo se formulará en cuatro secciones. La primera tratará sobre la metodología de investigación utilizada. En segundo lugar, describiré a NCP, su origen, la lógica que le da forma y la alianza política y corporativa que la promueve. Seguidamente expondré los resultados de investigación más salientes haciendo hincapié en consideraciones conceptuales presentadas en esta introducción. Por último, trataré el giro territorial en cuanto a una identidad colectiva ligada al lugar que manifiesta mecanismos culturales puestos en marcha para consolidar la resistencia vecinal.

\section{Metodología}

La investigación comenzó en abril de 2011 y se extendió hasta noviembre de 2014 para mi tesis de maestría en antropología social y política. Se implementaron técnicas cualitativas como la entrevista no direccionada y la observación participativa. Esta etapa se distinguió por una presencia de largo plazo en el campo. La indagación continuó entre 2014 y 2016 a través del contacto con miembros de asambleas vecinales y el seguimiento de material de difusión, documentación científica y novedades. Entre 2016 y 2018 tuvieron lugar dos incursiones en campo con el fin de incorporar nuevos actores políticos surgidos del recambio político del 2015, especialmente en la escena municipal. El abordaje multiactoral y la reconstrucción de interacciones a partir de ciertos eventos clave caracterizaron el trabajo de campo para poder comprender el devenir del conflicto.

El nuevo waterfront de Buenos Aires ${ }^{1}$ 
NCP nace en 2007 como una propuesta del grupo siderúrgico Techint a los intendentes de Avellaneda y Quilmes. La empresa, propietaria de 232 hectáreas distribuidas en el frente costero de estos dos distritos, intentaba replicar el éxito de Puerto Madero con la creación de un centro urbano para más de 25.000 habitantes. Para ello convocó a Oficina Urbana, un grupo de arquitectos que formularon un modelo de ciudad abierta basado en el planeamiento, la sustentabilidad ambiental y una nueva vida en sociedad. Lo que se intentaba, además, era poner en marcha un consorcio de articulación público-privada para este desarrollo urbano. De forma similar a la Corporación Puerto Madero, alguna vez gestionada por Oficina Urbana, aspiraba a llevar adelante las obras y generar condiciones para el crecimiento de NCP.

Se presentó a las comunidades de ambos distritos con fines de integración urbana, saneamiento y la promesa del regreso de la gente al Río de la Plata. "No es un proyecto inmobiliario", aclararon Fabio de Marco y Roberto Converti durante una entrevista realizada en diciembre de 2017; "este proyecto surge a partir de un compromiso que tenía Techint con su participación en el contrato en el CEAMSE [Cinturón Ecológico Área Metropolitana Sociedad del Estado]" ${ }^{2}$. Esto significaba la devolución de esas áreas ambientalmente regeneradas y urbanizadas con una infraestructura de servicios públicos. Los vecinos acusaron al grupo siderúrgico de haber accedido a la propiedad de esas tierras de forma ilegítima, ya que esa condición contractual debía cumplirse hacia 1998 y, por el contrario, durante los años 90 el Estado le transfirió a la empresa hectáreas naturales no afectadas por el enterramiento de basura.

NCP sería el proyecto de revitalización costera más importante de Latinoamérica, según anunciaban sus promotores en 2009, con una inversión billonaria que contemplaba torres residenciales de lujo de más de 40 pisos, hoteles 5 estrellas, canchas de golf y marinas privadas. La revalorización económica que evidenció esta zona estuvo dada principalmente por su ubicación, a sólo 10 min de la ciudad de Buenos Aires, y su conexión con el eje vial por medio de la autopista Buenos Aires-La Plata. Urbanizaciones privadas como Nuevo Quilmes, en Bernal, y otros desarrollos inmobiliarios en Berazategui también impulsaron la nueva ciudad. Así, "espacios abandonados y sin uso" intentaron convertirse en un nuevo eje urbano que uniría La Plata con la ciudad de Buenos Aires para llegar en el futuro a la ciudad de Rosario en una sola masa urbana. NCP fue una nueva representación del espacio que "vino a imponerse", alegaban los vecinos, derivada de una lógica particular de saberes racionales vinculados a las instituciones. Las diferencias han sido y continúan siendo legales, territoriales y ambientales, ya que éstas son áreas bajas que cumplen una importante función hidrológica en zonas de por sí inundables.

NCP vendría además a reemplazar grupos sociales por otros de ingresos altos, y a sustituir las prácticas tradicionales vinculadas a un estilo de vida ribereño que se distingue por el conocimiento de los ciclos del agua, de la biodiversidad y de las formas sustentables de explotar los recursos. Este modo de vida y de relación con la naturaleza es lo que vecinos, organizados en asambleas barriales, intentan evitar que desaparezca.

\section{ESPACIALIZACIÓN Y TERRITORIALIZACIÓN}

¿De qué se tratan ambos procesos y por qué son relevantes en el caso NCP? La espacialización es el acto por el cual un espacio asume una forma determinada, o, según otras definiciones, cuando cierto tipo de relaciones sociales son entendidas en función de un lugar. La territorialización, por su parte, conlleva la apropiación social de un territorio en el marco de relaciones de poder; es decir, no hay territorio que no haya sido moldeado por la territorialización. Esto significa para Porto-Gonçalves que el territorio es una categoría densa que supone:

un espacio geográfico que es apropiado y ese proceso de apropiación -territorialización- enseña identidades territorialidades- que están inscriptas en procesos siendo, por lo tanto, dinámicas y mutables, materializando en cada momento un determinado orden (2002, p. 230). 
Tanto en la espacialización como en la territorialización, el espacio interviene en el modo de producción a la vez que cambia con él; es un medio y un efecto. Los procesos que se dan en uno o en otro (la distinción es propia y a efectos de clarificar lo que expreso) son esencialmente políticos.

La espacialización contribuye al proceso de producción del espacio en términos de la experiencia de lo espacial, pero no permite explicar de qué forma los vecinos han desarrollado el apego e identificación que exhiben en cuanto a la ribera. La territorialización da lugar a que los sujetos se otorguen sentido a sí mismos construyendo identidades que devienen en formas propias de vincularse con el lugar (Betancourt Santiago 2017, p. 315).

Sin caer en cuestiones demasiado técnicas, ya que no intento hacer una antropología del espacio, lo que sí me interesa destacar es cómo una misma geografía admite abordajes que se complementan para comprender la totalidad de los elementos que están en juego.

Mi expectativa es que el lector recuerde que tanto la espacialización como la territorialización -o el "giro espacial" y el "giro territorial" como lo llaman algunos- permiten pensar cómo se produce el espacio urbano y cuáles son sus consecuencias.

\section{LA PRODUCCIÓN DEL ESPACIO COSTERO}

Dar cuenta de la complejidad del campo ha sido un desafío desde el principio de la investigación. Se observaba que las controversias no se dirimían exclusivamente entre aquéllos a favor y en contra de NCP, o entre sus promotores y las asambleas vecinales, sino que ellos simplemente hacían visibles sus posiciones a nivel público. Por el contrario, existían diferentes espacios dentro del espacio costero que generaban fricciones, a la vez que había prácticas por las que se enfrentaban éstos y otros actores. Los límites entre zonas protegidas o pasibles de ser habitadas, la indistinción entre propiedad privada y pública o las crecientes concesiones para usos particulares versus las actividades tradicionales como la producción hortícola y vitivinícola han sido algunos de los mecanismos más notorios de estos últimos años en la organización del lugar.

La falta de un plan de ordenamiento urbano en los distritos, instrumento previsto en la ley № 8.912 de ordenamiento territorial y uso del suelo de la provincia de Buenos Aires, ha redundado en la conformación del área costera como un rompecabezas desconectado del tejido urbano. En Quilmes sólo se ha realizado la delimitación preliminar de áreas y existen reformas a la zonificación según usos. Es decir, no existen objetivos territoriales a largo plazo que se implementen de manera sistémica, integral y participativa junto a la población ${ }^{3}$.

Los actores actuantes también son heterogéneos. Con otros intereses en la tierra y los recursos del lugar, los habitantes ribereños incluso mantienen posiciones distintas sobre la urbanización. En Bernal son aproximadamente 70 familias que habitan hacia la calle Espora, entre la autopista Buenos Aires-La Plata y el Río de La Plata. Si bien la población aumentó rápidamente y se expandió en la zona de humedales desde el anuncio de NCP, muchos de ellos se consideran "antiguos" en el sentido de que sus padres y abuelos se instalaron allí desde hace más de 40 años. Los "nuevos" residentes, que llegaron a partir de 2009, son acusados de ocupar tierras ilegalmente no por necesidad habitacional, sino por una cuestión especulativa, debido a que esta zona sería directamente afectada por las obras de construcción. Ya sea para tener una casa de fin de semana, para mantener negocios relacionados a la jardinería o para revender lotes fiscales, ellos se posicionarían en torno a la compensación económica que la posible gentrificación acarrearía. Algunos vecinos antiguos y asambleístas dicen que éstos realizan un "relleno hormiga" de áreas bajas y arroyos que parte del desconocimiento de los ciclos del río. Construyen sus casas de material impermeabilizando el suelo con losa en vez de erigirlas con pilotes, que es el modo tradicional de instalarlas para afrontar épocas de sudestada. Otro actor histórico con presencia activa en la misma zona es la Unión de Trabajadores (UST), conformada por ex trabajadores del relleno sanitario, quienes controlan el pasivo ambiental y realizan actividades comunitarias junto con los habitantes de la costa. 
En el sector de Avellaneda se encuentran las últimas familias de quinteros, quienes continúan resistiendo -cada vez en menor cantidad- la contaminación y el cambio de estatus de sus tierras por otros usos. Tan sólo en el último año estas personas fueron testigos de la habilitación legislativa local para la instalación de nuevos distritos industriales ${ }^{4}$, al mismo tiempo que se crearon espacios de protección ecológica en áreas linderas a éstos ${ }^{5}$.

Un elemento constante a lo largo de la costa, causante de la creación de basureros a cielo abierto, son las empresas de volquetes y los vertidos de escombros y ramas, producto de la poda municipal, con los que se rellenan humedales de forma ilegal.

Finalmente, están los protagonistas directos del conflicto. Por un lado están quienes reclaman la conservación de la costa como reserva natural con asambleas vecinales y organizaciones sociales, políticas y ecológicas de todo tipo a la cabeza, y, por el otro, los promotores de la urbanización con las autoridades municipales y Techint. La disputa engendró dos tipos de espacialidades, o dos diferentes modos de producción del espacio: aquella del poder y otra de la resistencia, ambas influyeron en las condiciones de la ribera. Los vecinos actúan in situ a través de la exploración de la costa para la clasificación de la biodiversidad y con el fin de crear nuevos recorridos para las actividades de difusión que organizan, con caminatas, jornadas de reforestación y avistamiento de aves. Es el lugar de la resistencia.

Los promotores, por su parte, obran en la esfera legislativa, territorial y política para el cambio de uso urbano. Esto se evidencia en dos hechos que habrían colaborado con la creación de espacios que se amoldan al master plan de NCP. Primero, el CEAMSE dispuso la creación de un bioparque metropolitano (2018) sobre el antiguo relleno sanitario de Villa Domínico, que corresponde a los espacios de acceso público que tendrá la nueva ciudad. Son 343 hectáreas de superficie donde hay depositadas más de 47.660.000 toneladas de residuos, actualmente en etapa de post cierre, con el tratamiento de gases, líquidos lixiviados y control de aguas superficiales. Segundo, la promulgación de la ley No 14.888 en diciembre de 2016 para el ordenamiento de áreas naturales en la provincia de Buenos Aires, bajo los términos de la ley nacional No 26.331 de presupuestos mínimos de protección ambiental de bosques nativos. Conocida en los medios locales y regionales de comunicación como "Ley Techint", significó para las asambleas vecinales un traspié en la defensa de la costa.

De acuerdo a documentos e informes científicos que los vecinos publicaron entre 2014 y 2016, las áreas de conservación se habrían reducido en un alto porcentaje para que NCP pudiera obtener la habilitación ambiental del Organismo para el Desarrollo Sostenible (OPDS). Así, zonas de alto grado de conservación (rojas) fueron reemplazadas por otras de valor medio (amarillo) y estas a su vez por zonas aptas para la urbanización (verde).

Los organismos provinciales merecen un capítulo aparte ya que su accionar ha recibido duras críticas de diferentes sectores sobre su rol en el avance de emprendimientos inmobiliarios en zonas protegidas. Ellos también han contribuido a la forma en que ciertos procesos urbanos y ambientales han incidido negativamente en la población ${ }^{6}$.

¿Cómo encastrar entonces las actuaciones y las visiones del lugar que se registraban y en base a qué? Los encuentros y desencuentros de los últimos 10 años pudieron ser examinados con los momentos de producción del espacio (Lefebvre 1974, p. 33; Oslender 2016, p. 28; Pintos 2003, p. 11; Soja 1996, p. 66). A mi entender no son espacios de tiempo que pueden ubicarse en una línea cronológica, sino que, más bien, se definen por las prácticas materiales y simbólicas que los determinan. Son de carácter interdependiente y no tienen duración, por lo que generan así un fenómeno que es continuo y que siempre está en desarrollo. Veamos esto con un poco más de detalle.

Las prácticas espaciales son el resultado de la actividad humana e implican las diferentes formas derivadas de la generación, uso y apropiación del espacio. Estas prácticas, en su conjunto, producen una cierta espacialidad que está ligada a la posición relativa de individuos y grupos. En lo cotidiano, podría decirse que son las iniciativas que los vecinos llevan a cabo en la arena política para enfrentarse con el gobierno municipal 
y Techint. Concretamente, y retomando lo que mencionaba anteriormente, esto se plasmó en la creación de un espacio desde donde se organizan para oponerse a NCP. Estar en el lugar les permite estar alertas, pero también saber qué es lo que defienden y cómo hacerlo. En conclusión, es una forma de apropiación que se funda en las relaciones sociales con los habitantes de la ribera y entre miembros de asambleas vecinales, y que a su vez origina otras formas de reinventar el lugar.

...y bueno, ¿cómo nos apropiamos del lugar? Por los nenes cuando llegamos acá no sabíamos cómo y empezamos a hacer talleres (...) y el primer contacto que nosotros tuvimos acá fueron ellos y que la confianza se fue dando por el trabajo con los niños (Vecina de Bernal durante encuentro semanal de Asamblea no a la entrega de la costa, 31 Diciembre 2017).

Como puede verse, el valor de las relaciones sociales resulta fundamental para la generación de este tipo de procesos colectivos ligados a la costa.

Las representaciones del espacio constituyen el espacio conceptualizado de planificadores, arquitectos y científicos. Es un orden que se establece por vía del control del conocimiento, de los signos y códigos, que se convierten en los medios para descifrar y para intervenir en la producción espacial. Este espacio se impone porque se sustenta y se justifica a través del conocimiento técnico que se encuentra ligado al aparato institucional del poder.

Es dominante porque se materializa en lo discursivo y en lo escrito, no sólo desde la legislación, sino a través de mapas y gráficos que refuerzan una lógica.

Estos factores se verificaron en el rol que los desarrolladores urbanos tuvieron para la justificación del proyecto en distritos que ya habían sufrido los efectos del relleno sanitario administrado por SyUSA (empresa del grupo Techint) entre 1978 y $2004:$ “...este espacio, que uno hoy lo ve vacío es el crecimiento futuro en toda el área metropolitana” (Entrevista Fabio de Marco, 2017).

Para adecuarse a esta visión, las autoridades de Avellaneda recurrieron a la rezonificación de su ribera. Aunque en 2005 la Secretaría de la Producción de ese municipio destacaba que allí vivían unas 280 personas, que mantenían una microcultura y rasgos agrarios de altísimo valor cultural y ecológico -y que era imprescindible preservar las condiciones naturales ${ }^{7}-$, tres años después el Concejo Deliberante optó por asignarla como zona de gestión especial para su urbanización -ordenanza 21.332/08-. Este cambio encontró nuevas justificaciones en otros tecnicismos y prioridades urbanas.

Los espacios de representación están saturados de significados y se desarrollan en relación a las representaciones dominantes del espacio. De acuerdo a Soja (1996, p. 67), comprende a los otros dos momentos de la producción espacial. En este momento de producción del espacio se encuentran no sólo las representaciones espaciales del poder, sino el poder de las representaciones espaciales.

La costa sur del Río de La Plata es para Oficina Urbana un espacio de naturaleza que puede ser intervenido ${ }^{8}$, en el que el paisaje se amolda a una visión que se corresponde con el urbanismo. La misma contrasta con los vecinos, que piensan en ella como un corredor biológico que proporciona conectividad entre áreas naturales similares hacia el norte y sur de la provincia de Buenos Aires.

Lo que busca apropiarse por parte de los actores en el caso bajo análisis tiene dos aspectos: lo que el espacio es y lo que puede llegar a ser. Un caso y el otro no dejan de ser utopías en función de algo imaginado y que posee atributos altamente deseables.

Ambos, la ciudad y la reserva natural, ofrecen una vida social diferente, pero en definitiva son lugares no existentes. Uno porque aún no se ha materializado y estaría lejos de serlo, y el otro porque invoca elementos prístinos que se contradicen con características predominantemente antrópicas.

El contexto en que la producción espacial se desarrolla es definido por vecinos, funcionarios y la empresa como de dominación y resistencia, lo que indica los mecanismos, estrategias y representaciones que expresan esas relaciones de poder en el territorio.

NCP vino a ser una instancia catalizadora en el devenir de la costa y su importancia estuvo dada en poner en debate cuestiones urbanas y ambientales que se encuentran pendientes de resolución desde hace tiempo. 
Reunió geográficamente cuestiones como la calidad del agua, la transferencia de tierras a privados, el manejo de la basura, las inundaciones, las napas freáticas y el ordenamiento de bosques.

Hasta aquí quisiera plantear el análisis desde la variable espacial Lefebvriana.

A continuación me concentraré en el concepto de territorio y en cómo permite examinar el comportamiento de las asambleas vecinales en este contexto. La espacialización, como puede verse, no es sólo el espacio sino la temporalidad práctica que convierte un espacio en otro (Santos, 1994, p. 23). Para una mejor interpretación de los hechos habría que remontarse a 1960, cuando la zona aún era pública. La territorialización tiene que ver con procesos en los que los sujetos se dan sentido a sí mismos, a lo que hacen, y de esta manera construyen identidades en relación a un lugar.

\section{EL TERRITORIO: PERTENENCIA E IDENTIDAD COLECTIVA}

Según afirma Milson Betancourt Santiago, el "giro territorial” es un salto cualitativo de la visión espacial, que se potenció en las últimas décadas en torno a conceptos nacidos de las conflictividades protagonizadas por movimientos campesinos e indígenas (2017, p. 313).

El territorio surge ligado a la dignidad, a la autonomía y al buen vivir por parte de quienes rechazan que el mismo sea apropiado y/o expropiado por intereses que no sean comunes. Se combina así la lucha por los derechos de la naturaleza con la concepción de un territorio determinado y una territorialidad, o, lo que es lo mismo, una identidad de características propias. Carlos Walter Porto-Gonçalves, Arturo Escobar y Enrique Leff también han trabajado sobre el tema y destacaron, por su parte, la valorización de saberes que propugnan quienes se unen por la defensa de la tierra.

Dicho de modo muy generalizado, el proceso es comparable con el de Avellaneda y Quilmes, por cuanto los vecinos producen una identidad política colectiva que defiende una particular construcción territorial. El territorio no es una concepción homogénea que puede definirse por la suma de voluntades, sino que nace de la diversidad ideológica, política y social para constituir formas de ser, estar y vivir la ribera. Al igual que en el análisis de Betancourt Santiago, esta concepción se engendró en la confrontación con la de una territorialidad hegemónica.

¿Y cómo se ha dado esto? Inicialmente podría hablarse del sentido de lugar que se sustenta en orientaciones subjetivas derivadas de una experiencia con el espacio (Oslender, 2016, p. 35):

...yo creo en el territorio, sí entiendo que a veces hay cuestiones que hay que hablarlas o que por ahí se necesita un espacio físico como para organizar con electricidad y la PC y otras cuestiones, y a veces la lluvia, el frío, a veces acá hemos soportado inviernos, se pone heavy [difícil], pero para mí es súper importante hacerlo acá, en el río o en el desmonte poner un cartel, trabajar ahí, apropiarnos, es de todos, es de nosotros, no lo hacen los funcionarios, hagámoslo nosotros, lo vamos a defender nosotros (Entrevista con vecina de la Asamblea No a la entrega de la costa, 25/11/2017).

Sin embargo, hablar de sentido de lugar no explica enteramente las formas en que los vecinos reaccionan. A la experiencia de lugar podría agregarse la memoria como forma de gestar un vínculo con el territorio (Relph, 1976). Para Buttimer (1976, p. 284), la relación humana con un territorio es de carácter dialógico, porque es construida sobre la memoria no sólo personal, sino colectiva. Es una interrelación mutua entre el lugar y los sujetos en la que uno influye sobre el otro.

Otro factor de incidencia podría ser la vivencia compartida de contaminación que Javier Auyero y Débora Swistun (2009) definen como "sufrimiento ambiental"; es decir, vivir en el peligro, la incertidumbre y en muchos casos convivir con la enfermedad. El deterioro de las aguas del Río de la Plata -y arroyos que desembocan en él (Sarandí, Santo Domingo, Jiménez) -, así como la cercanía con el Polo Petroquímico de Dock Sud y la cuenca Riachuelo-Matanza, la falta de control de industrias en zonas residenciales y el deterioro de espacios públicos los lleva a sostener un territorio cuyos servicios ambientales ${ }^{9}$ evitarían el empeoramiento de una situación que ya los afecta. 
Por lo tanto, entiendo a la identidad vecinal como una fuente de significado y experiencia (Castells, 2010, p. 6). La misma se caracteriza por apropiar cualidades de la geografía en disputa. Es una forma de autoconocimiento, que brinda un entendimiento de sí y de la realidad, y que se construye a partir de recursos culturales y de un trasfondo histórico (Escobar, 2008, pp. 208-217). Recrea, además, discursos y prácticas específicos que son simultáneamente reconocibles por otros.

En esta última sección voy a examinar dos elementos que distinguen a esta identidad vecinal asamblearia. Lo haré desde una óptica más bien descriptiva, casi ontológica, en función de qué es lo que hace a esta identidad y cómo se interrelacionan ciertos elementos en la resistencia.

En primera instancia haré mención a la representación de bienes comunes que los vecinos adjudicaron en el espacio costero. Son los bienes comunes los que mejor condensan la interrelación entre resistencia y lugar en cuanto a lo que les pertenece y tienen derecho a proteger. Luego examinaré a la nostalgia que representa a NCP como una amenaza.

\section{Bienes comunes}

La ribera como bien común emerge del proceso de aprendizaje en el que las asambleas vecinales se embarcaron en 2008 en un esfuerzo por entender qué ocurría en ese espacio. Significa algo que es de todos, que debe ser accesible para todos y cuyos beneficios no pueden privatizarse. Por esta razón, no debe ser entregada a intereses privados o corporativos que intenten lucrar con ella generando ventajas para pocos y costos que se distribuyen para el resto de la población.

La idea de bien común entre los vecinos de Avellaneda y Quilmes contiene dos dimensiones, una filosófica en cuanto a valoraciones simbólicas y otra compulsiva en cuanto a su capacidad para hacer cumplir algo. La primera tiene que ver con el "buen vivir". Conservar las propiedades naturales del lugar tiene que ver con querer estar bien, con la posibilidad de una vida mejor, con respirar aire no contaminado, contar con un lugar de acceso público que pueda disfrutarse junto al río. La segunda opera en términos de obligación entre los vecinos y hacia los municipios, a los que interpelan como principales responsables de una forma de gestionar el suelo urbano y los recursos naturales de los distritos.

La posibilidad de que estas áreas puedan ser explotadas económicamente no es una opción, ya que la desaparición de un sector de bosque nativo y humedales impactaría en el funcionamiento del resto del ecosistema, que es comprendido como un todo.

Los vecinos pretenden evitar la "tragedia de los comunes" (Hardin, 1968), en el sentido de que un sistema de recursos compartidos utilizado por usuarios individuales según su propio provecho y de forma contraria al bien común conduce indefectiblemente a la destrucción de esos recursos. Idealmente lo que intentan lograr es la inclusión de "usuarios prudentes" para cooperar voluntariamente con la regulación de la costa. Esto se alinea con lo que propone la economista política Elinor Ostrom (1990), quien contraría a los que afirman que sólo la propiedad privada o la regulación gubernamental pueden evitar el colapso de la naturaleza.

Tal como los define Gabriela Merlinsky, entonces, los bienes comunes son:

...aquella parte del entorno que rebasa el ámbito de la posesión individual, pero respecto del cual la persona tiene un derecho reconocido de uso, no para producir mercaderías, sino para la subsistencia de sus congéneres (2017, p. 249).

El derecho que los vecinos se adjudican toma fuerza sobre todo en la percepción de negligencia de los gobiernos municipales para aplicar las leyes que declaran reserva natural a ciertas zonas de la ribera ${ }^{10}$.

A pesar de contar con la protección legal que declara garantía de por vida para sus habitantes, la contaminación y el abandono se han transformado en la normalidad de éstos y de los visitantes. Parte del poder político de las asambleas reside en la reivindicación colectiva de sus derechos lo que les permite actuar no sólo en nombre de todos, sino de generaciones venideras.

"Era muy feliz en esos momentos": la nostalgia 
Las palabras que titulan esta subsección pertenecen a Alejandra, una vecina de Bernal que se mudó a San Fernando hace ya unos años y que me escribió por correo electrónico en noviembre del 2016 para expresar qué lugar ocupa la ribera en su vida y qué significa para ella.

Sus recuerdos de niñez y adolescencia, de momentos compartidos en este lugar en otros tiempos, es representativo de un sentir que atraviesa a muchos otros vecinos entrevistados.

La ribera se afianza en estos relatos como un ámbito común, pero también como la recreación de ciertas relaciones en torno a la naturaleza y el río. A nivel colectivo adquiere la dimensión de aquello que los nuclea, la idea de pertenencia, y es aquí donde surge la memoria, y, en consecuencia, la nostalgia. Añoranza de un paisaje, de un río no tan contaminado, del disfrute, de tener un lugar donde escaparse. Ya sea en bicicleta o a pie, algunos evocan la llegada a los balnearios para pescar con padres y abuelos, para divertirse después de clases con amigos o reunirse en celebraciones familiares alrededor del mate.

El recuerdo tiene que ver con la historia personal pero también con la historia compartida.

La "desgracia del CEAMSE", como dicen algunos vecinos, aquello que vino a contaminar, a restringir y a alejar a la gente del río fue un antes y un después en la lucha popular local.

El cierre del relleno sanitario en 2004 fue vivenciado como un logro conjunto, cuyo alcance se extiende hasta el presente. Muchos de los vecinos movilizados en ese entonces continúan reclamando cuestiones públicas que giran alrededor de la costa.

La nostalgia cobra dimensión fundamental en su compromiso activo con el cambio social, en la formación de su identidad política colectiva (Angé \& Berliner, 2015).

Es una reacción al progreso que busca instalarse con la urbanización. Anticipa un sentimiento de pérdida; es lo que falta o lo que no volverá a ser. Adquiere la fuerza de una memoria subalterna con capacidad de resistencia a otras interpretaciones de la historia y de lo que sucedió en la ribera. El control del territorio costero es una condición para mejorar la calidad de vida, así como para la recreación y consolidación de prácticas y valores ligados a él. Prácticas y valores que han cobrado un nuevo significado para los vecinos, y que con el tiempo han devenido en nuevas implicancias políticas y ecológicas a nivel local y regional para otros embarcados en una resistencia similar.

\section{Conclusiones}

La ribera sur del Gran Buenos Aires revela una intensificación en los modos de su producción espacial que ha incidido, concretamente desde el año 2008, en una reorganización que va más allá de sus circunstancias físicas. Las tensiones que se derivan de este proceso han contribuido, así como el accionar de diversos actores, a la recreación del conflicto por NCP. La triada Lefebvriana presentada brevemente en este artículo resaltó cómo algunos y otros representan el espacio costero y actúan en consecuencia.

Puede concluirse que el espacio analizado es un producto social donde se despliegan estrategias de poder, así como la construcción y circulación de diversas clases de conocimiento. Tanto el "giro espacial" como el "territorial” permitieron la integración de enfoques para interpretar la complejidad de las fuerzas descriptas.

Se ha aspirado así a contribuir al análisis de una forma de disputa creciente por los últimos espacios públicos y naturales del contexto urbano. La espacialización brindó los elementos para comprender el aspecto político por el cual la ribera se convierte en un objeto de control y poder. La territorialización aspiró a mirar la forma en que los hechos en torno a la costa influyeron en una concepción particular de la misma referenciando y transformando a los vecinos que la sostienen.

El conflicto, entendido más allá de la mera polarización y desde una perspectiva espacial, lleva a comprender cómo se implementa un modelo concreto de urbanización. Por otro lado, permite apreciar el rol que la naturaleza tiene en esto. Pero, sobre todo, qué lugar tienen los habitantes para decidir sobre aquello que les interesa y cómo pueden hacerlo. Las particularidades del movimiento vecinal muestran justamente esto. 


\section{REFERENCIAS}

Angé, O. \& Berliner, D. (Editors). (2015). Anthropology of Nostalgia. New York, Oxford: Berghahn Books.

Auyero, J. \& Swistun, D. (2009). Flammable: Environmental Suffering in an Argentine Shantytown. Oxford University Press.

Betancourt Santiago, M. (2017). Colonialidad territorial y conflictividad en Abya Yala/ América Latina. En H. Alimonda, C.Toro Pérez y F. Martín (Coord.), Ecología politica Latinoamericana:pensamiento crítico, diferencia latinoamericana y rearticulación epistémica (pp. 303-350), 1a ed. Ciudad Autónoma de Buenos Aires: CLACSO; México: Universidad Autónoma Metropolitana; Ciudad Autónoma de Buenos Aires: Ciccus.

Buttimer, A. (1976). Grasping the Dynamism of Lifeworld. Annals of the Association of American Geographers, 66(2), 277-292.

Castells, M. (2010). The Power of Identity. 2nd ed. [Oxford:] Wiley-Blackwell Publishing.

De la Fuente Fernández, R. (2002). Cartografía de la resistencia. Transformaciones del espacio social en Chiapas. Revista CEMOS Memoria. Revista mensual de politica y cultura, 157, 22-26.

Escobar, A. (2008). Territories of Difference. Place, Movements, Life, Redes. Durham and London: Duke University Press.

Hardin, G. (1968). The tragedy of the commons. Science, 162(3859), 1243-1248.

Harvey, D. (2012). Rebel cities. From the Right to the City to the Urban Revolution. London: Verso.

Lefebvre, H. (1974). La production de l'espace. Paris: Anthropos.

Leff, E. (2014). La apuesta por la vida. Imaginación sociológica e imaginarios sociales en los territorios ambientales del sur. México: Siglo XXI.

Marcús, J. (Coord.) (2017). Disputas por la producción sociocultural del espacio urbano en la Ciudad de Buenos Aires. Buenos Aires: Editorial Teseo.

Merlinsky, G. (2017). Los movimientos de justicia ambiental y la defensa de lo común en América Latina. Cinco tesis en elaboración. En H. Alimonda, C. Toro Pérez, F. Martín (Coord.), Ecología política latinoamericana. Pensamiento critico, diferencia latinoamericana y rearticulación epistémica (vol. 2, pp. 241-264). Ciudad Autónoma de Buenos Aires: CLACSO; México: Universidad Autónoma Metropolitana.

Ostrom, E. (1990). Governing the commons: The evolution of institutions for collective action. Cambridge: Cambridge University.

Porto-Gonçalves, C. W. (2002). Da geografia às geo-grafias: um mundo em busca de novas territorialidades. En A. Ceceña y E. Sader (Orgs.), La guerra infinita: hegemonia y terror mundial (pp. 217-256). Buenos Aires: CLACSO.

Oslender, U. (2016). The Geographies of Social Movements. Afro-Colombian Mobilization and the Aquatic Space. Duke University Press.

Pintos, P. (2003). El espacio insurgente. Retratos de la espacialidad de la resistencia social en la Argentina contemporánea. Estudio de caso: Movimiento de Trabajadores Desocupados de San Francisco Solano (MTD Solano) (Tesis de maestría). Universidad de Barcelona, España.

Relph, E. (1976). Place and Placelessness. London: Pion.

Santos, M. (1994). Los nuevos mundos de la geografía (discurso). En Discursos correspondientes a las Investiduras de Doctor "Honoris Causa" (pp. 15-25). Madrid: Universidad Complutense.

Soja, E. W. (1996). Thirdspace: Journeys to Los Angeles and Other Real-and-Imagined Places. Cambridge: WileyBlackwell.

Swyngedouw, E. (2004). Social Power and the Urbanization of Water. Oxford University Press. 


\section{Notas}

1 Así se titulaba un folleto de 2009 que describía a Nueva Costa del Plata (NCP) y era distribuido por Techint a interesados y stakeholders potenciales del desarrollo urbano. Aludía a NCP como "un lugar único frente al río", fundándose en características de calidad de vida: “a) waterfront: gran extensión del borde costero para el uso ciudadano, que integra el río al espacio urbano. Esto hace que la ciudad mire y viva el río al lado de notables espacios verdes protegidos; b) insularidad: por las características de su acceso que evidencia un concepto de insularidad u oasis, que favorece las condiciones de seguridad y la sensación de tranquilidad en un espacio inmerso en la naturaleza, pero muy accesible a todo lo externo; c) ciudad-icono: con edificios emblemáticos y construcciones innovadoras y originales por su arquitectura y tecnología, lo cual la convierte en un atractivo residencial, turístico y comercial” (pág.7).

2 Contrato puesto en vigor vía decreto 2.038/77 dentro del marco de la ley 20.705 para el cumplimiento de los fines y mecanismos previstos en pos del funcionamiento de la sociedad "Cinturón Ecológico Área Metropolitana Sociedad del Estado” representada por la Municipalidad de la Ciudad de Buenos Aires y del Poder Ejecutivo de la Provincia de Buenos Aires. CEAMSE tenía como objeto (artículo 4, Título II): a. Planificar, proyectar y ejecutar, por sí o mediante contratación con terceros, la disposición final de residuos sólidos de Buenos Aires, proponiendo la afectación necesaria para que quede integrado un anillo forestado rodeando toda el área metropolitana y la Capital Federal. b. Llevar a cabo los programas de urbanización dentro de las normas de planeamiento urbano que la Sociedad proponga y la Provincia de Buenos Aires apruebe, pudiendo transferir a particulares hasta un máximo de un tercio de área total, contemplando las necesidades de que las urbanizaciones queden integradas formando un conjunto armónico con el sistema de parques regionales. La tercerización de la administración del relleno sanitario en Villa Domínico, Avellaneda, establecida en el inciso a se realizó a través de SyUSA (Saneamiento y Urbanización Sociedad Anónima), una empresa del Grupo Techint creada especialmente para tal fin.

3 Arquitectos de Quilmes. Octubre 2008. “Bases para un Plan de Ordenamiento Urbano del Partido de Quilmes”. Documento presentado en el marco de la convocatoria decreto 4.183/08, Municipalidad de Quilmes.

4 No se indica autor (15/5/2017). Polémica por la rezonificación de las quintas de Sarandí. El termómetro. Información con temperatura. Recuperado de: https://eltermometroweb.com/2017/05/15/polemica-la-rezonificacion-las-quintassarandi/

5 No se indica autor. (15/3/2018). Ferraresi inauguró la Reserva Natural de Avellaneda. La Ciudad. El Diario de Avellaneda. Recuperado de: https://laciudadavellaneda.com.ar/ferraresi-inauguro-la-reserva-natural-avellaneda/

6 Este punto es mencionado en los informes publicados por la a) Comisión Asesora del Comité de Cuenca del Río Luján (Noviembre 2012) y b) la Facultad de Ingeniería, Departamento de Hidráulica, de la Universidad Nacional de La Plata publicado también en ese mismo año a raíz de las trágicas inundaciones ocurridas en Luján, La Plata, Berisso y Ensenada: a) Inundación: un informe apunta a las especulaciones inmobiliarias" (30/11/2012) El civismo. Bisemanario de la ciudad de Luján. http://www.elcivismo.com.ar/nota.php?nota=14640 b) http://www.ing.unlp.edu.ar/institucional/difusion /2013/inundacion_informe

7 Secretaría de la Producción. Subsecretaría de Medio Ambiente y Recursos Naturales. Municipalidad de Avellaneda. (Julio 2005). Zonas de reserva ecológica. Publicado a través de la Secretaría de Cultura, Educación y Promoción de las Artes. http://www.culteducaavellaneda.com.ar/noticias/wmprint.php?ArtID=120

8 Entrevista del 13 Diciembre 2017 junto a Roberto Converti y Fabio de Marco.

9 Algunos de los servicios ambientales reivindicados por los vecinos para la protección de humedales son: control de inundaciones, reposición de aguas subterráneas, estabilización de costas y protección contra tormentas, depuración de aguas, reservorios de biodiversidad, mitigación del cambio climático y adaptación a él.

10 El bosque nativo ribereño de Bernal fue declarado "Reserva Los Sauces" por ordenanza No 8255/ 96. La ordenanza 9348/02 del Concejo Deliberante de Quilmes definió como zona de reserva ecológica a la selva marginal de este distrito para su protección. La ordenanza No 9.508 del 2003 modificó estos límites para ampliarlos. 